\title{
O Paço de Concelho e a Torre Sineira da Igreja Matriz de Vila do Conde no Século XVI: Algumas Questões
}

\author{
José Ferrão Afonso ${ }^{1,2}$, Guilhermina Cadeco ${ }^{3}$ \\ ${ }^{1}$ CITAR, Escola das Artes, Universidade Católica Portuguesa, Porto, Portugal \\ 2 CEAU, Faculdade de Arquitetura, Porto, Portugal \\ ${ }^{3}$ Escola das Artes, Universidade Católica Portuguesa, Porto, Portugal
}

\section{Resumo}

Dois edifícios quinhentistas de Vila do Conde, o Paço do Concelho e a torre sineira da Igreja Matriz, exemplificam dois aspetos importantes da arquitetura do Renascimento italiano introduzida no Norte de Portugal por Francesco de Cremona, arquiteto do bispo de Viseu D. Miguel da Silva: uma austeridade monumental com raízes em Alberti e o gosto antiquário dos arquitetos romanos do início do século XVI.

\section{Palavras chave}

Arquitetura, Renascimento, Vila do Conde, Francesco de Cremona, Paço do Concelho, Torre da Igreja Matriz.

\section{Los edificios del Paço de Concelho y de la Torre Sineira de la Iglesia Matriz de Vila do Conde (Portugal). Algunas cuestiones.}

\section{Resumen}

Dos edificios del siglo XVI en Vila do Conde, el Ayuntamento y el campanario de la iglesia parroquial, muestran dos facetas importantes de la arquitectura renacentista introducida en el Norte de Portugal por Francesco de Cremona, arquitecto del obispo de Viseu D. Miguel da Silva: una austeridade monumental com raíz en Alberti y el gusto anticuario de los arquitectos romanos.

\section{Palabras clave}

Arquitectura, Renacimiento, Vila do Conde, Francesco de Cremona, "Paço do Concelho", Campanario de la "Igreja Matriz".

The two Sixteenth-century buildings of the Town Hall and the Bells Tower of the Matrice Church of Vila do Conde. Some relevant topics

\begin{abstract}
Two sixteenth-century buildings from Vila do Conde, the Paço do Concelho and the bell tower of the main church show two important aspects of the Renaissance architecture introduced in the North of Portugal by Francesco de Cremona, the architect of the bishop of Viseu D. Miguel da Silva: an albertian type monumental austerity, and the antiquarian taste of the roman architects.
\end{abstract}




\section{Keywords}

Architecture, Renaissance, Vila do Conde, Francesco de Cremona, "Paço do Concelho", Bell Tower of the "Igreja Matriz".

\section{Introdução}

O Paço do Concelho de Vila do Conde a vizinha torre sineira da Igreja Matriz são dois programas arquitetónicos quinhentistas, fulcrais na definição espacial da praça real da vila, que colocam interessantes questões em termos da arquitetura do século XVI no Entre-Douro-e-Minho. Ambos exibem uma forte influência do Renascimento italiano, sendo o Paço, concluído em 1543 por mestres portugueses, atribuído ao italiano Francesco de Cremona, enquanto a empreitada da torre da Matriz foi executada por João Lopes-o-Moço e rematada em 1581, embora este mestre não tenha, provavelmente, sido o seu único projetista. Procurou-se, portanto, através de uma análise formal dos dois edifícios e da pesquisa bibliográfica e documental, esta levada a efeito no Arquivo Municipal de Via do Conde, obter dados adicionais, mais precisos, sobre a sua construção, influências e possíveis autores.

\section{O Paço do Concelho: de Vila do Conde a Urbino}

O Paço do Concelho de Vila do Conde foi concluído em 1543 e o nome dos seus mestres, Aparício Gonçalves e Gonçalo Afonso, era conhecido (Neves, 1987: 75-79). Contudo, desses dois mestres apenas um, Gonçalo Afonso, foi autor do projeto patrocinado por D. João III, sendo João Lopes, então morador em Azurara, o outro autor da traça (Sousa, 2013: 79). Este último é o conhecido mestre pedreiro João-Lopes-o-Velho (ca.1480-1556) que, desse modo, estaria, nessa altura, à frente das obras da matriz dessa povoação do outro lado do Ave. A Igreja Matriz de Azurara é, no seu conjunto, uma construção tardo-gótica, com exceção da torre sineira, que Ihe é posterior. Aliás, João Lopes foi praticante desse tipo de arquitetura, muito marcada pelo hispano-flamengo, a que são adicionados alguns elementos ornamentais renascentistas apreendidos em livros de modelos como o Codex Escurialensis ou, mais tarde, no popular tratado Medidas del Romano, de Diego de Sagredo (1526).

O Paço do Concelho, contudo, tem sido atribuído a Francisco de Cremona (Moreira, 1988: 22), o muratore italiano que o bispo de Viseu D. Miguel da Silva trouxe consigo de Roma e para o qual projetou uma série de programas arquitetónicos, sobretudo em Viseu e na Foz do Douro (Moreira, 1988) ${ }^{1}$. Saliente-se que D. Miguel foi também abade do mosteiro beneditino de Santo Tirso, onde ordenou um conjunto de intervenções, sobretudo na igreja, e Gonçalo Afonso, ainda como pedreiro, trabalhava nessa obra em $1528^{2}$. Em Vila do Conde, ele assumiu a responsabilidade pela execução do projeto e só alguns anos depois, em 1543, quando a obra se concluiu, João Lopes é chamado para integrar a equipa de avaliadores que, pela sua parte, a verificam, indicando-se, então, que era morador já não em Azurara, mas no Porto (Sousa, 2013: 80). A atribuição a Francisco de Cremona, portanto, não deverá ser posta em causa pelos dados documentais suprarreferidos.

Um episódio ocorrido quase contemporaneamente no Porto faz também pensar numa autoria do italiano. Em Dezembro de 1539, um ano após a carta real que ordena a construção do Paço de Vila do Conde, Cremona é chamado, com Diogo de Castilho, para se pronunciar sobre a reparação da Torre da Câmara, surgindo então a proposta de construção de um corpo adossado a ela e do apeamento do seu andar superior (Basto, [s.d.]: 260-264]). A obra não avançou, mas o resultado seria de uma horizontalidade similar à do Paço de Vila

\footnotetext{
${ }^{1}$ Ver, sobre o mesmo tema, José Ferrão Afonso (Afonso, 2014: 233).

2 Arquivo Distrital do Porto, K/16/1-71, Prazos de S. João da Foz, 1528, Setembro 1, fl. 44 vo.
} 
do Conde, inovadora em relação à tradicional tipologia do edifício camarário português e formalizada numa planta retangular alongada e numa fachada sem torres ou merlões. $O$ simbolismo anamórfico da torre deu lugar à exposição representativa de uma fachada de dois pisos, com uma escadaria exterior que ascende transversalmente ao andar nobre e se conclui num patamar com peitoril para onde abre a porta principal, em posição mediana, sob o frontão triangular. Este exibe um experimentalismo formal sem paralelo no Portugal da época (Caetano, 2011: 1, 482), sendo mais um sinal da origem italiana do desenho (Fig. 1).

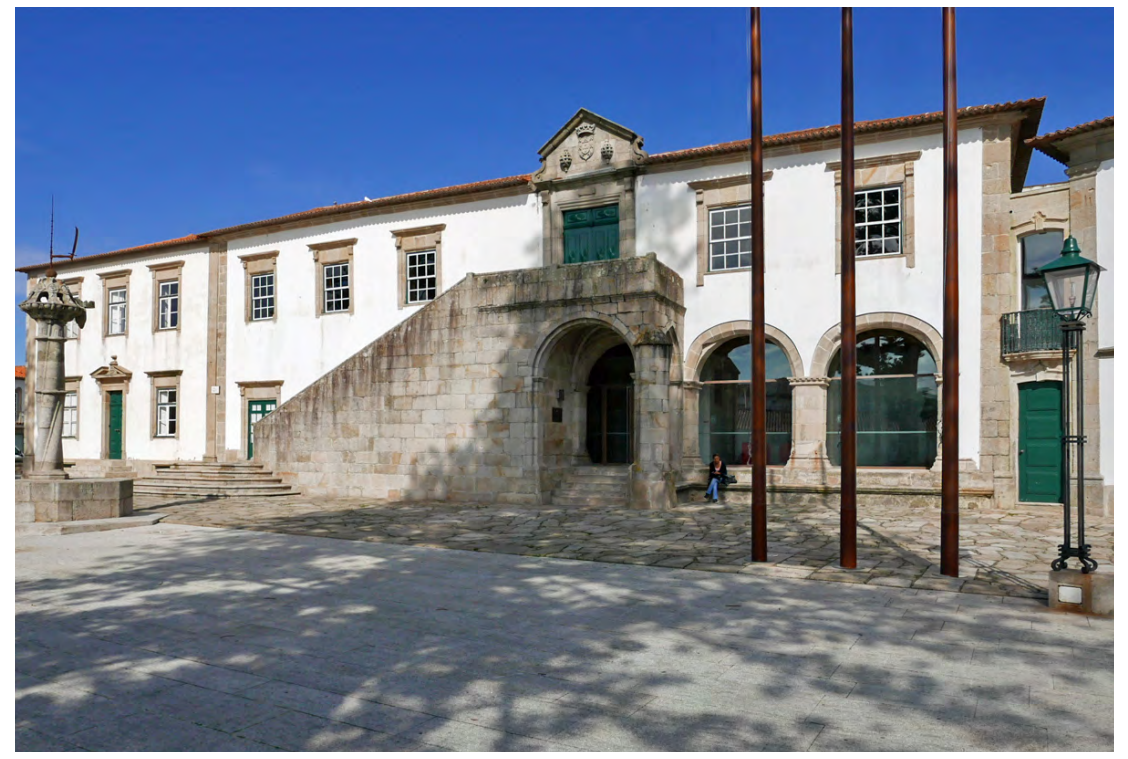

Figura 1 - Paço do Concelho de Vila do Conde (@ António Sabler).

Na fachada do Paço de Concelho de Vila do Conde nota-se a sugestão do frontispício do Paço Abacial de D. Miguel da Silva na Foz, construído por Cremona na década de trinta (Moreira, 1995:339) (Fig. 2).

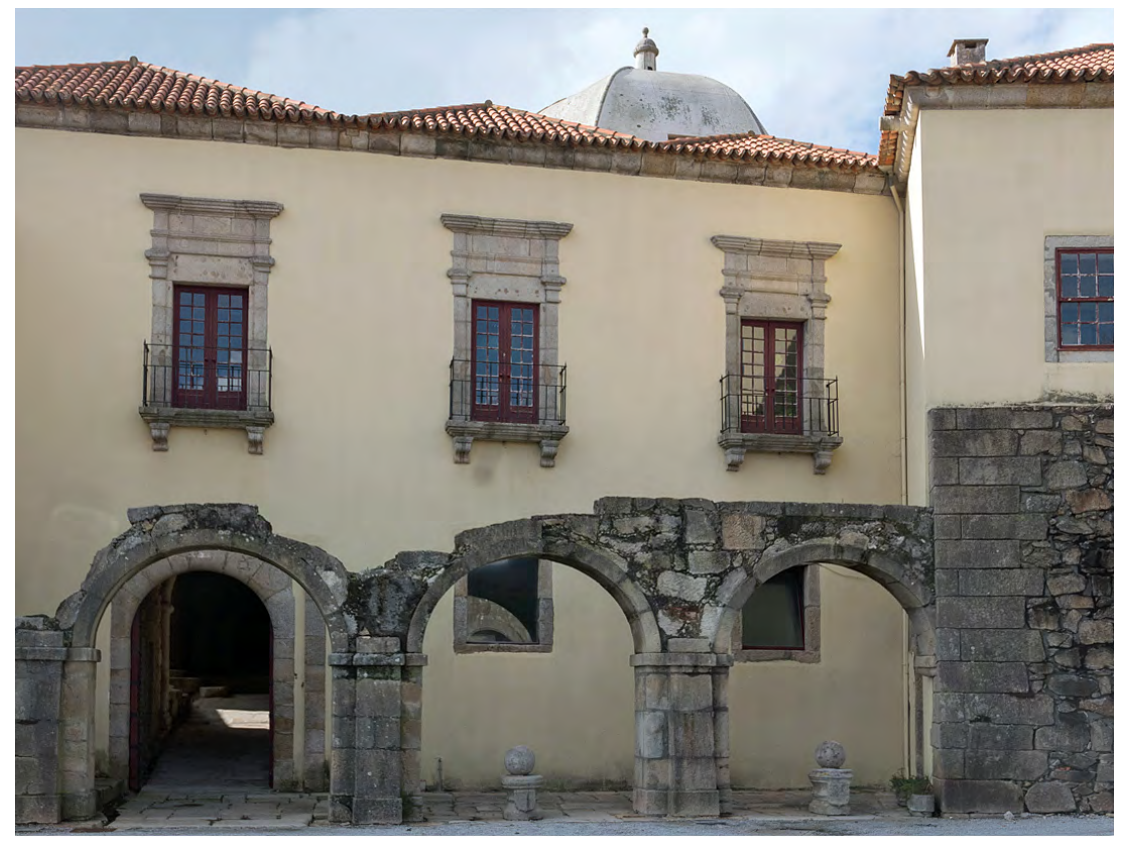

Figura 2 - Fachada do Paço Abacial de S. João da Foz do Douro (ㄷ António Sabler). 
Aliás, não só uma série de detalhes tipológicos, mas o estruturalismo seco e monumental que o muratore de D. Miguel da Silva praticou no programa da Foz do Douro se inspiram, em boa medida, na obra do arquiteto senense Francesco di Giorgio, ${ }^{3}$ por sua vez devedora da monumentalidade desornamentada de Alberti e do seu conceito de arquitetura murária. No Paço Concelhio, porém, eles são condicionados pela tradição gótica, que a prática dos executantes não consegue ultrapassar. Assim, sob o patamar das escadas surgem, no interior dos pilares ainda medievais, as primeiras pilastras toscanas da arquitetura nortenha, demonstradoras da vontade de organicismo da arquitetura humanista (Fig.3) e o alpendre, à direita da escadaria, é suportado por arcos sobre pilares quadrangulares ${ }^{4}$, embora com detalhes ornamentais ainda tardo-góticos (Fig.4).

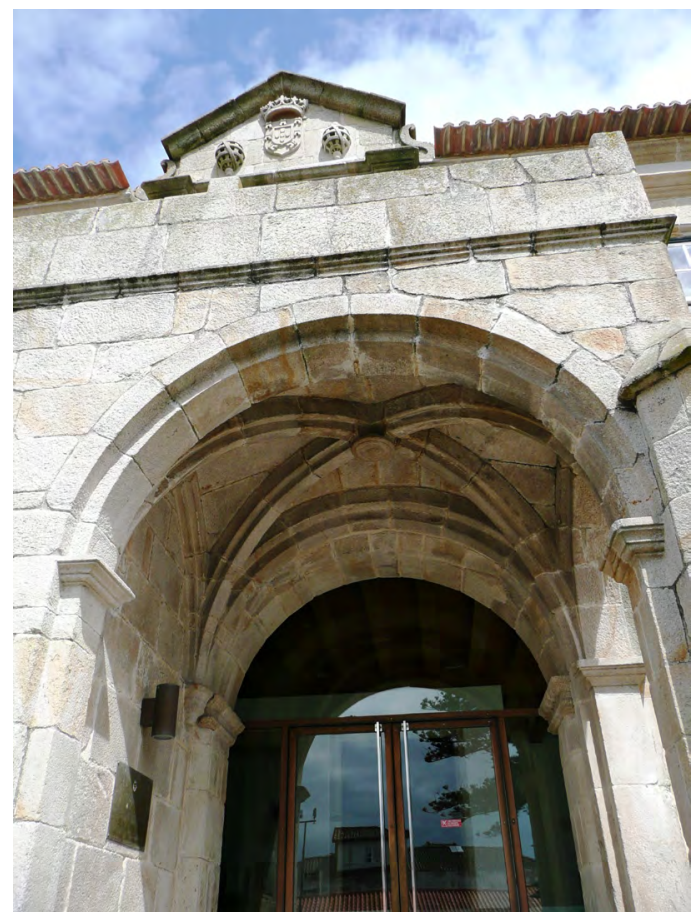

Figura 3 - Pilastras do alpendre do paço, sob a o patamar da escada exterior (๔) José Ferrão Afonso).

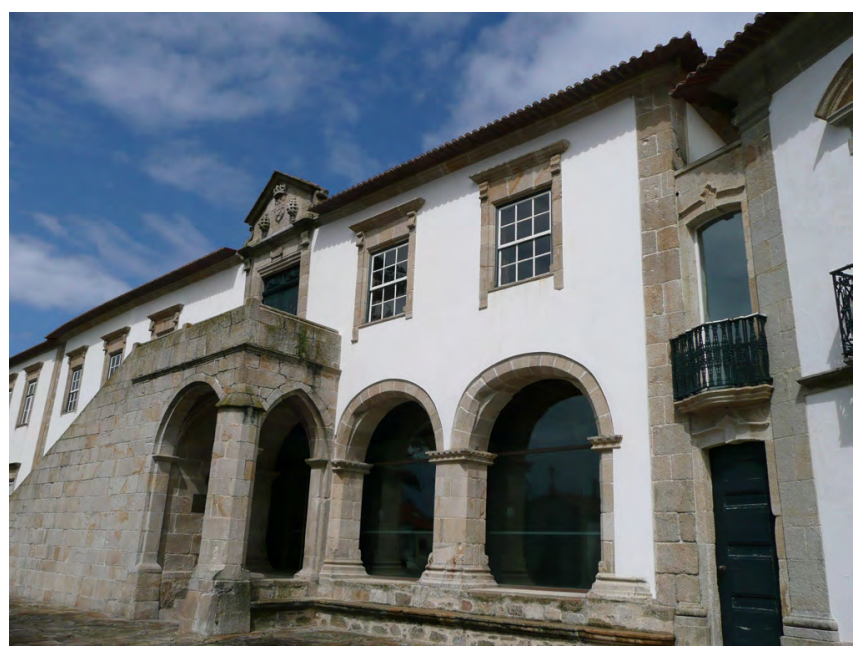

Figura 4 - Arcadas sobre pilares do paço (@ José Ferrão Afonso).

\footnotetext{
${ }^{3}$ Ver, sobre o ascendente de Francesco di Giorgio na obra portuguesa de Cremona: (Amoruso et al., 1991) ; (Oliveira, 1998: 23); (Oliveira, 2004:II, 543) (Afonso, 2014); (Afonso, 2015).

${ }^{4}$ Carlos Caetano atribui os pilares à época tardo-manuelina, afirmando o seu carácter vernáculo, e que pertenceram aos primitivos açougues (Caetano, 2011:1, 464). Estes, porém não se localizaram aí, mas nos Paços do Concelho anteriores, situados na chamada Praça Velha (Sousa, 1513 : 71).
} 
Apesar desses anacronismos, as pilastras, os pilares e os arcos sobre eles são inovadores e podemos, por exemplo, encontrar na justificação para a utilização destes, em substituição de colunas, os princípios supramencionados da arquitetura murária "estruturalista". Francesco di Giorgio, para além de arquiteto, foi engenheiro militar durante a sua estadia em Urbino (ca. 1477-1485), ao serviço do duque Frederico Montefeltro, o que terá influenciado essa sua aproximação à arquitetura. Desse modo, arcadas sobre pilares toscanos surgem no claustro de S. Bernardino em Urbino e nos pátios do Palácio Comunal de Jesi e da fortaleza de Sassocorvaro (Fig.5).

Quanto ao piso superior da fachada do Palácio Ducal dos Montefeltro voltada ao pátio, ele é igualmente, segundo Fiore, projeto do senense (Fiore, 1984:78). A fachada do Paço Abacial da Foz e a do Paço Concelhio vila-condense podem ter-se inspirado em princípios aí desenvolvidos. Em Vila do Conde, porém, existiu uma interpretação bem mais fruste do conceito original, expressa no ruído gótico presente em alguns detalhes formais como a cornija e as gárgulas. Contudo, os vãos, encarados como ornamento, destacam-se bem da estrutura da parede, atuando como partes sobrepostas e subsidiárias dela. Por outro lado, ainda segundo modelos com origem em Urbino, as referências à Antiguidade são, essencialmente, mediatas e alusivas, sendo sugeridas, de forma indireta, pela monumentalidade e pela inserção, quase minimalista, de alguns elementos decorativos caracterizantes (Bruschi, 2010:23).

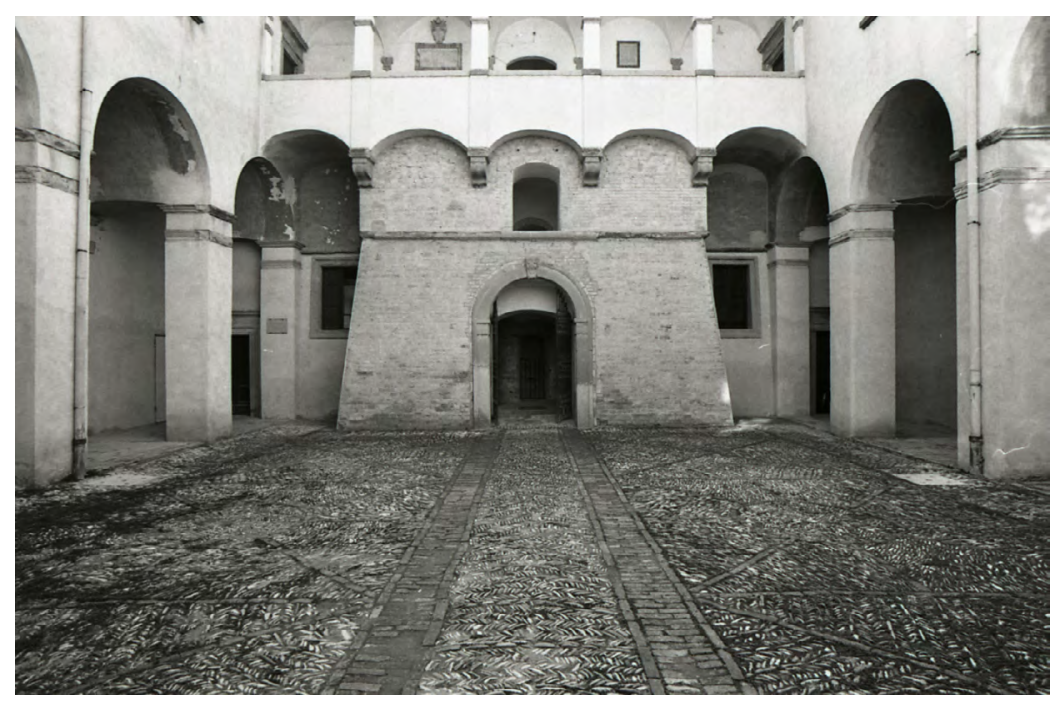

Figura 5 - Pátio da fortaleza de Sassocorvaro (@ Paolo Monti).

Urbino parece, desse modo, ter tido um importante papel na formação de Cremona. Por exemplo, no Claustro da Sé de Viseu (Fig. 6), a arquitrave jónica que corre sobre os arcos e se repete no interior da nave da igreja matriz da Foz - é um elemento comum na obra de Francesco di Giorgio. Por sua vez, os ressaltos formados nos encontros da arquitrave com os elementos verticais que sustêm as páteras são, igualmente próprios do seu desenho e seriam retomados por um dos seus principais continuadores, Bramante ${ }^{5}$. O arquiteto do tempietto foi outra influência bem discernível na obra de Cremona na Foz: na planta compósita do Farol de S. Miguel-o-Anjo, nos seus nichos interiores ou no entablamento com uma inscrição latina que corre nos remates das quatro fachadas. Originalmente implementada no claustro de Urbino por Di Giorgio, o mesmo tipo de faixa seria retomada no palácio romano da Chancelaria, em que Bramante desempenhou um papel decisivo (Bruschi:

${ }^{5} \mathrm{O}$ modelo do claustro de Urbino é tido como referência para o do palácio da Chancelaria, em Roma, atribuído por Susana Abreu, no seguimento de uma posição tradicional, a Baccio Pontelli, que a mesma investigadora indica como tendo marcado a obra de Cremona (Abreu, 2010 :571-573). 
2010: 290). Poderá Cremona ter sido o filho de um companheiro de Bramante em Urbino, que depois, já como jovem adulto, o reencontrou em Roma? Seja como for, ele surge a trabalhar em três pontes da Magliana, nos arredores da cidade papal, em 1511 (Bertolotti, 1985: 12). Esta obra esteve possivelmente associada à villa homónima, cujos trabalhos foram dirigidos por Bramante, então arquiteto de Júlio II entre 1507 e 1513. Como se sabe, em 1514 Cremona operava ainda como muratore em S. Pedro do Vaticano, onde pode ter estado sob as ordens de Bramante, que viria a falecer nesse $a n 0^{6}$.

Urbino foi a capital do humanismo "perspético" ou "matemático" dos finais do Quattrocento, e a sua corte foi frequentada por nomes como Piero de la Francesca, o espanhol Berruguete, o florentino Boticelli, Rafael e, possivelmente, Alberti. Bramante esteve em Urbino como arquiteto e pintor de perspetiva, provavelmente entre 1472 e 1476 e foi igualmente marcado, na sua fase inicial, pelo ideal da arquitetura murária de Alberti e o conceito de ornamento a ela associado (Bruschi, 2003:17). Vimos que eles tinham já informado Di Giorgio e, por essa via, poderão ter sido transmitidos a Cremona. A cidade ducal, a sua corte e o brilho da sua vida cultural, de onde emerge um segundo Renascimento, senhorial e pós-florentino, que muito marcou a Roma humanista de Júlio II, eram um modelo áulico que tinha todas as condições para sensibilizar o aristocrata D. Miguel da Silva. Nesse sentido, Sylvie Deswarte refere que Castiglione, o amigo de D. Miguel, foi embaixador em Roma do duque de Urbino Francesco Maria della Rovere entre 1513 e 1516 (Deswarte, 1989: 28). $\mathrm{Na}$ dedicatória do Cortegiano ao português, o autor salienta que, na base desse endosso, estava o desejo de fazer conhecer ao embaixador português os "homens excecionais" que tinham abrilhantado a corte ducal do filho de Frederico, Guidobaldo de Montefeltro, falecido em 1508, que o português não tinha tido oportunidade de conhecer (Deswarte, 1989:27). A escolha de Cremona pode, por conseguinte, ter-se devido ao seu conhecimento de dois mundos: o de Urbino e o de Roma, capitais no imaginário humanista do duque de Viseu.

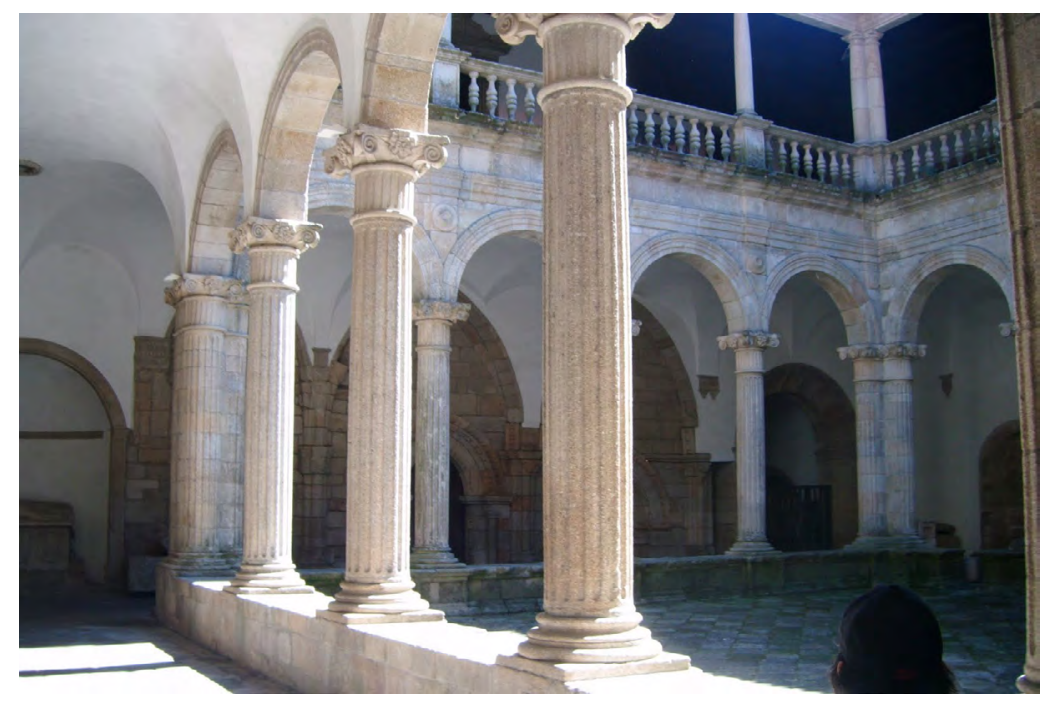

Figura 6 - Claustro da Sé de Viseu (ㄷ José Ferrão Afonso).

O ascendente de Urbino na cultura arquitetónica importada por Cremona é também patente na pintura de um seu contemporâneo, o viseense Vasco Fernandes, igualmente ao serviço de D. Miguel da Silva. Essa ascendência é sobretudo patente no Pentecostes, executado para o mosteiro de Santa Cruz de Coimbra em 1534-1535 (Fig.7), e numa obra em que colaborou, Cristo em Casa de Marta e Maria (ca. 1535-1540). No primeiro, os pilares da abside central exibem um capitel com forma de arquitrave, que funciona como uma síntese

${ }^{6}$ Frommel, Christop Luitpold - Die Peterskirch unter Papst Juliu II im Licht neuer Dokumente. In: Römisches Jahrbuck für Kunstgescichte, 16, 1976, 57-136, 80, n. 79, citado por Rafael Moreira (Moreira, 1988:11). 
abreviada da ordem arquitetónica. Os capitéis, "condensados" na arquitrave, prolongamse, no interior da abside, abraçando a base do quarto de laranja. Essa morfologia é uma afirmação do sintetismo organicista muito utilizado pelo arquiteto senense no seu período de Urbino e por ele registado nas suas pesquisas antiquárias. No segundo caso, a abertura que se distingue à esquerda é inspirada no portal da rampa helicoidal do palácio ducal, desenhada por Francesco Di Giorgio: o arco redondo sobre pilastras do portal encurva-se, na verdade, dentro de uma segunda ordem de pilastras. Esta continua as primeiras, após arrancar de capitéis "abreviados" e remata-se no entablamento superior, dotado de um espesso dintel, em que se repete a ordem menor (Fiore: 1993: 89).

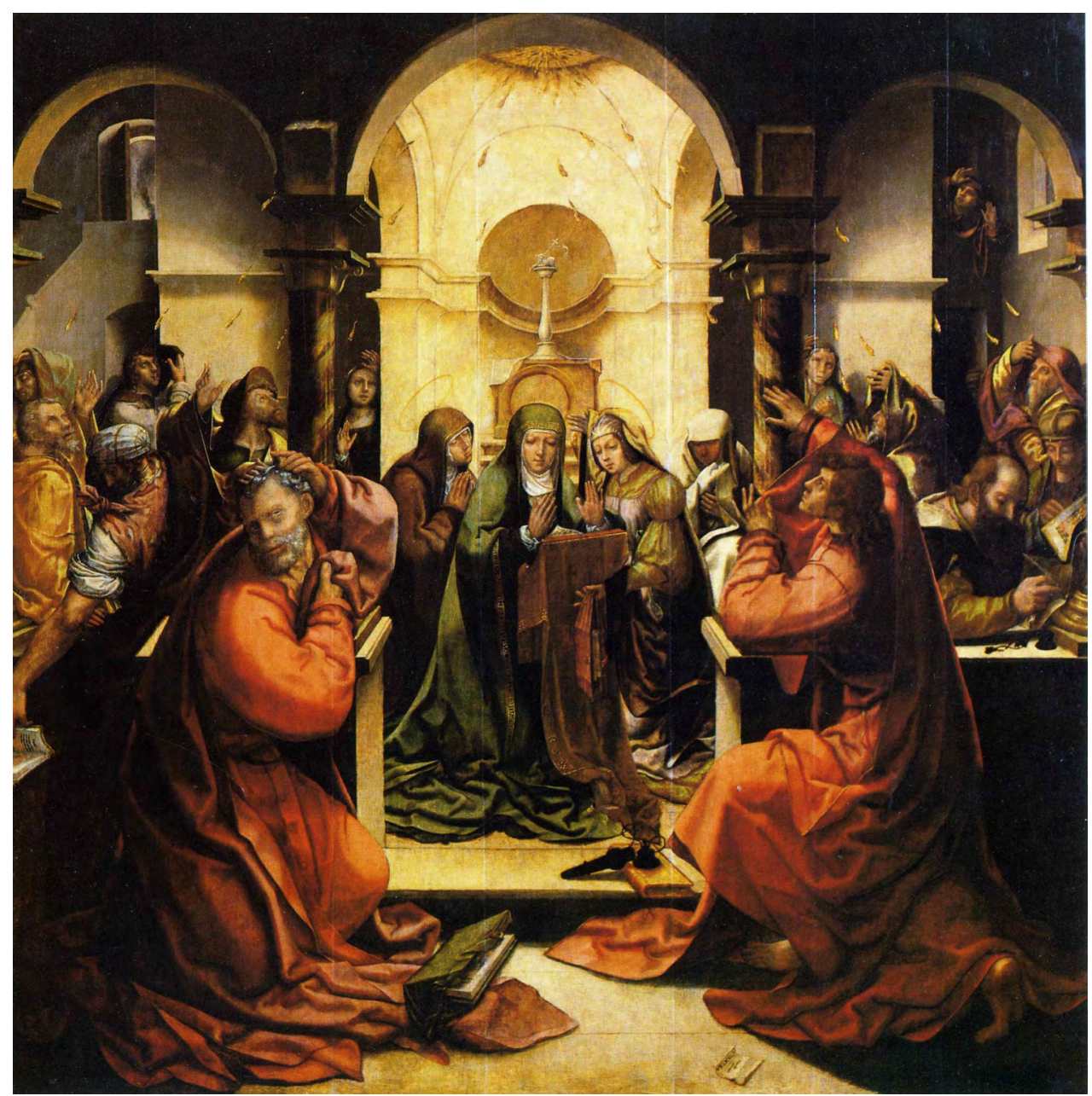

Figura 7 - Vasco Fernandes - Pentecostes (1534-1535) (Wikimedia Commons).

A continuidade de Urbino na arquitetura romana, a proximidade a Bramante e a disponibilidade de uma fonte iconográfica maior como eram os Tratatti do arquiteto senense poderiam, por isso, ser um importante contributo para explicar a obra portuguesa de Cremona. Do mesmo modo, as suas capacidades profissionais de arquiteto-engenheiro justificariam o carácter fragmentário e o pragmatismo como essas influências foram entendidas; características que seriam acentuadas quando os seus colaboradores portugueses as tentaram emular. Assim, se a obra do paço teve impacto no percurso de João Lopes, este optou por adaptar o estruturalismo seco de Cremona a um gosto tradicional que via no Renascimento, essencialmente, uma arte decorativa, feita de detalhadas sugestões antiquárias não sublimadas pela estrutura. Como se referiu, o seu papel no projeto, se existiu, deve ter sido secundário; talvez se associasse a ele como uma forma de garantir a sua qualidade, já que era bastante conhecido e apreciado no Norte. 
Outra obra contemporânea, que João Lopes executou, reflete o mesmo classicismo desornamentado e mostra páteras idênticas às que surgem no claustro de Viseu: o chafariz de S. Domingos, no Porto (1544). É, portanto, possível que tivesse ocorrido uma colaboração com o muratore, desde 1540 sem patrono, pois D. Miguel da Silva tinha neste ano fugido para Itália. A capela de S. Bernardo na Sé de Viana (1547) sugere também um projeto do português, embora inspirado, sobretudo no que se refere às pilastras estriadas, no arco cruzeiro da capela-mor da matriz de S. João da Foz.

A atração de João Lopes pela afirmação estrutural do arquiteto de D. Miguel da Silva rapidamente cederá o passo a um decorativismo alegre, mais consentâneo com a tradição gótica, a sua formação e o gosto da sua clientela. Ele patenteia-se rapidamente na sua obra vianense (Casa dos Lunas; Casa Sá Sotomayor) (Fig.8), embora a lição de Cremona não seja aí completamente renegada.

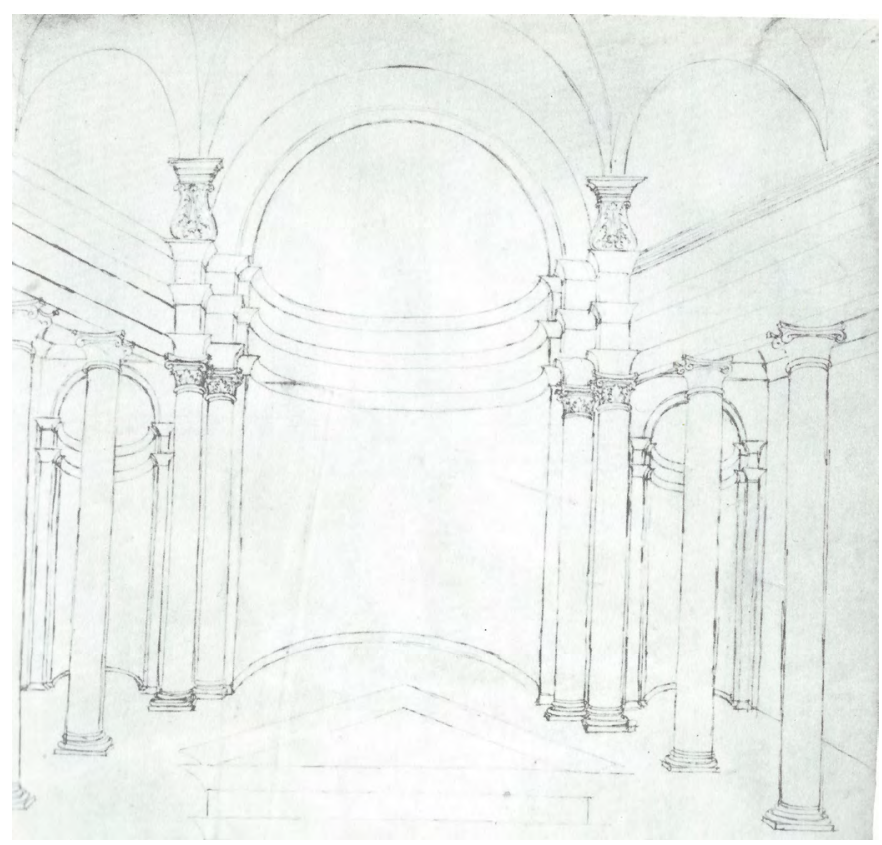

Figura 8 - Francesco di Giorgio Martini - Interior de S. Salvador de Spoleto (Tratatti di Architettura Ingegneria e Arte Miitare. A cura di Corrado Matese, Transcrizione di Livia Matese Degrassi. Tomo I, Codice Torinense Saluzziano 148, f.93 TAV 173. Milano: Il Polifilo, 1967.

\section{A torre sineira da Matriz de Via do Conde e os "estudos do antigo"}

A torre sineira da Igreja Matriz de Vila do Conde, vizinha do Paço do Concelho, que João Lopes-o-Moço (1530-1595), um dos filhos de João Lopes, se comprometeu a construir em 1573, viria a ser concluída em 1581 (Fig.9). Cunha e Freitas afirma que ela fora ordenada por D. Manuel I e devia, inicialmente, implantar-se frente ao pórtico da igreja, para além de ser erguida sobre arcos. Em 1569, porém, a vereação decidiu solicitar ao monarca a mudança da torre para o local, à esquerda do frontispício, onde atualmente se encontra, e o abandono dos arcos. A obra não iria arrancar de imediato e, quando João Lopes a assumiu em 1573, foi-lhe entregue pelos vereadores o projeto da sineira, que o mestre se obrigou a respeitar (Freitas, 2001:128-133). De secção quadrangular e rematada por uma cúpula, a torre é constituída na sua totalidade por blocos de granito retangulares de orientação horizontal, afeiçoados externamente. Os silhares a partir do primeiro sobrado são lisos e definem, de maneira geral, uma aparência muito homogénea. Os da base evidenciam um lavrado distinto, exibindo as faces almofadadas e um aspeto mais grosseiro. No seu conjunto, aparentam ser uma estrutura semelhante a um podium romano. 


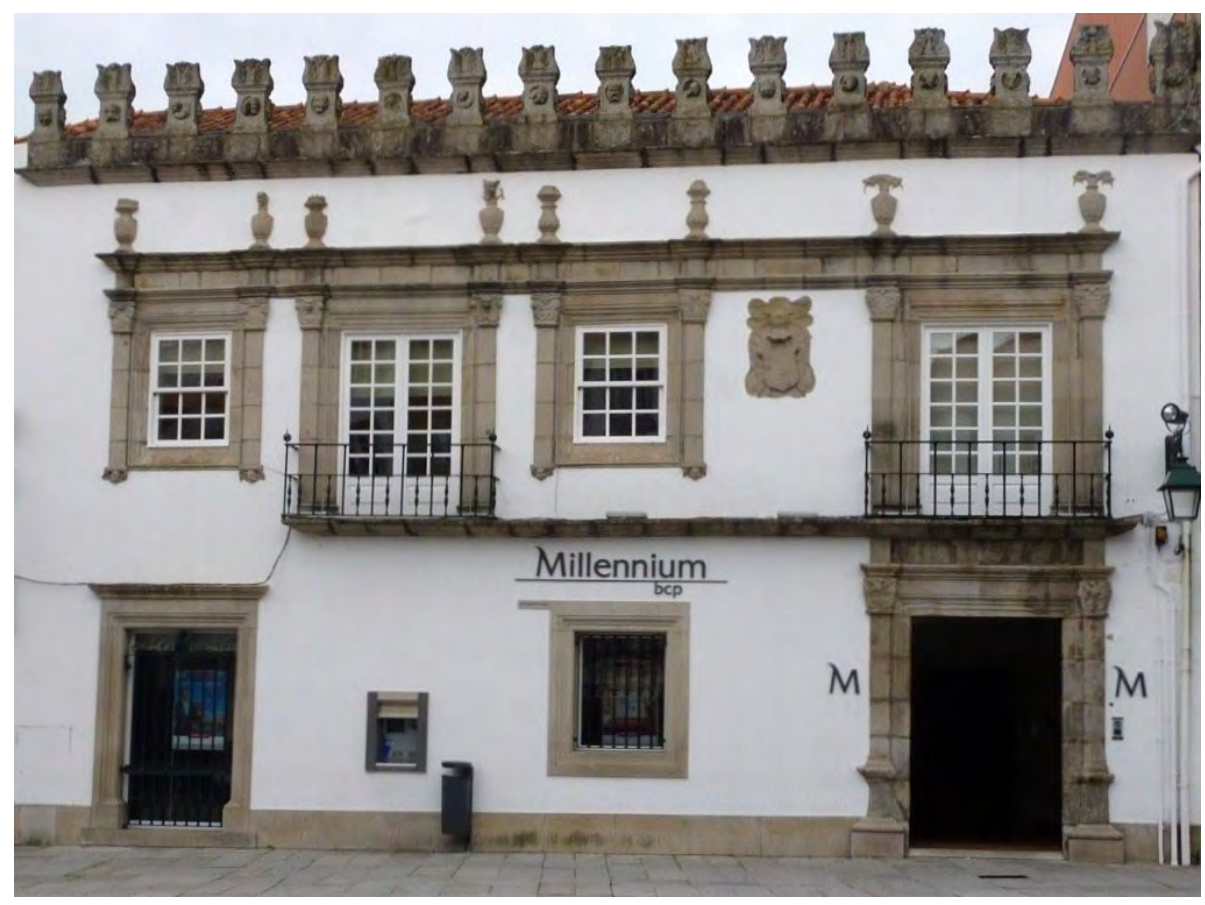

Figura 9 - Casa Sá Sotomaior, Viana do Castelo (www.monumentos.pt).

Como se referiu acima, em nenhum lado se indica que João Lopes-o-Moço tenha sido o autor do desenho da torre. Nas atas camarárias, aliás, registou-se uma alteração sua ao plano que the foi entregue quando do início da obra. Este previa inicialmente apenas a existência de frestas, e a janela de sacada voltada a poente foi rasgada por sua iniciativa, tendo executado o desenho para ela7. Existe, porém, uma referência na documentação camarária que aparenta ser relativa à pedra da base da torre. No dia 29 de Outubro de 1548 , os vereadores tinham acordado que se demolisse a Igreja de São João o Velho "... que ora as freiras meteram no cerrado que fazem se deribe e a pedra della por ser muito boa e bem lavrada fosse para ajuda da torre dos sinos que se a de fazer na igreja de Sam Joam nova e que a dita pedra venha logo para junto da igreja desta vylla..." (Freitas, 2001: $132)^{8}$. A igreja demolida era pré-românica, existindo pelo menos desde o século $X$ e dava o nome a um antigo castro, nomeado em documentação medieval (Polónia, 1999: I, 121) e situado no local em que se construirá o mosteiro no início do século XIV. Terá sido essa a pedra reutilizada na base da torre sineira?

O reaproveitamento de materiais de construção provenientes de edifícios mais antigos ou sem uso foi uma prática corrente ao longo das diversas épocas históricas, em todo o espaço europeu (Fabião, 1995) ocorrendo por pragmatismo e economia de meios, uma vez que as pedras já estavam cortadas e afeiçoadas. Essa hipótese já foi considerada, por exemplo, por Eliana Sousa (Sousa, 2013: 62-63). Esta investigadora, contudo, considera as pedras da base da torre silhares rusticados, portanto posteriores à época romana. $O$ almofadado utilizado na época romana (Adam, 1989, Rua, 1998), pode ser visto em várias construções existentes no território português. Contudo, os silhares que constituem o podium, como afirma Eliana Sousa, não são romanos; a sua aparência tosca e picada, que se praticou a partir do Renascimento, deverá ser resultado da utilização de um instrumento de percussão direto, como por exemplo um martelo de talhe, tipo de efeito utilizado mais tardiamente. Sendo assim, o que terá sucedido às pedras trasladadas da igreja antiga de S. João?

\footnotetext{
${ }_{7}$ Arquivo Histórico Municipal de Vila do Conde, Livro 6 de Vereações, 1573, Outubro 19, fl. $189 v^{\circ}$.

${ }^{8}$ Cunha e Freitas cita o AHMVC, Livros de Vereações, vol. III, 1547-1552, fl. 177vo.
} 
Uma informação histórica poderá ser-nos útil. Em 1547, um ano antes da referência à deslocação da pedra, o portuense Gonçalo Baião (act. 1521- ca. 1572) relatara, por carta escrita ao rei D. João III em 15 de Setembro, que tinha cercado um jardim junto do mosteiro, o que permitira a sua frequência pelas freiras (Viterbo 1988: 94). Ou seja, foi em consequência desse encerramento do jardim que a igreja de S. João foi demolida e a pedra deslocada. Gonçalo Baião, para além de praticante de arquitetura, humanista e conhecedor de Alberti, era um entendido em Antiguidades, visitara Roma e estudara os seus monumentos. A pedra proveniente da Igreja Velha de S. João pode, por conseguinte, ter sido transportada para junto da Matriz por sua ordem. Ela, com efeito, aparenta ter sido reutilizada, não no podium, mas no interior da torre, na base da caixa de escadas quadrangular que ascende, a partir do seu primeiro piso, até ao campanário superior. Junto a essa caixa de escadas, uma outra, semicircular, abriga a escadaria helicoidal de acesso ao coro; esta é mais antiga e data da época da construção da igreja. Assim, o podium rusticado e a torre sobre ele, que envolveram essas estruturas adossadas ao tramo esquerdo do frontispício, são-Ihes sequentes.

O rusticado do embasamento é idêntico ao que surge na base da designada "Casa da Roda", nas traseiras da capela-mor da Sé de Braga, datável dos meados do século XVI (Fig. 10). A sua inspiração poderia estar em fontes iconográficas como os Tratatti de Francesco di Giorgio, ele próprio um praticante dos "estudos de antigo". Com efeito, o tipo de almofadado existente, quer na torre de Vila do Conde quer na base da casa bracarense, aparenta reproduzir o do podium do templo do Divo Claudio, em Roma, registado pelo arquiteto senense (Fig. 11). No mesmo desenho, surge igualmente uma porta com aduelas idênticas à que se rasgou no flanco sul da torre, junto do frontispício da igreja (Fig.12). A utilização do rusticado deveria estar, por essa razão, associada a uma prática antiquária, de raiz humanista, que teve o seu expoente máximo no programa empreendido por D. Miguel da Silva na Foz do Douro a partir de 1525 e que se extingue nos meados do século.

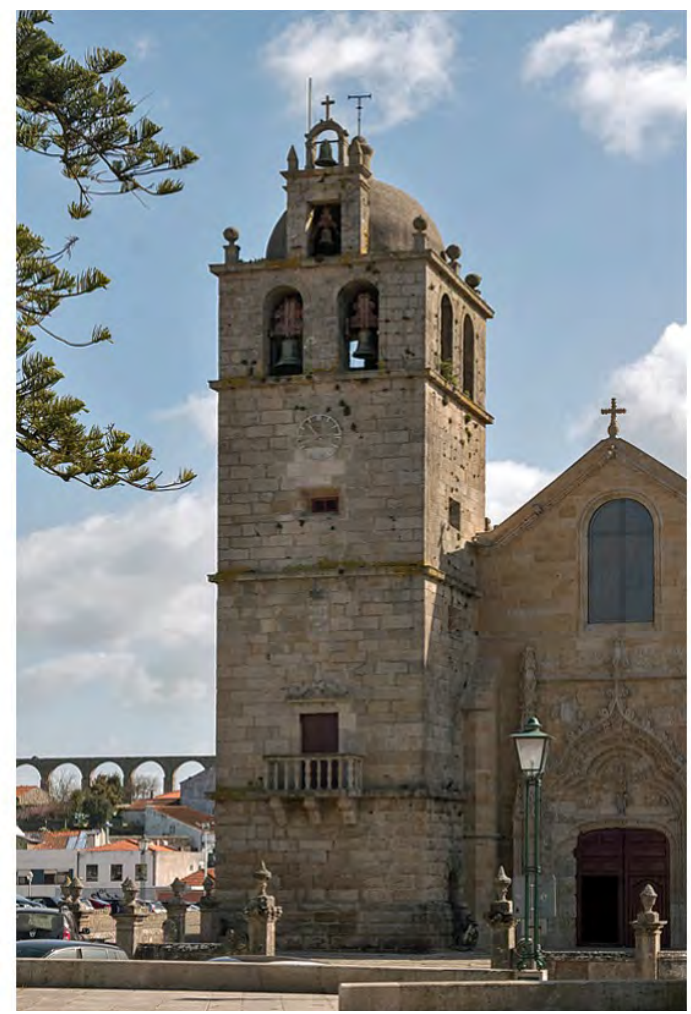

Figura 10 - Torre da igreja matriz de Via do Conde (@ António Saber). 




Figura 11 - Pormenor do rusticado do embasamento da torre (ㄷ Guilhermina Cadeco).

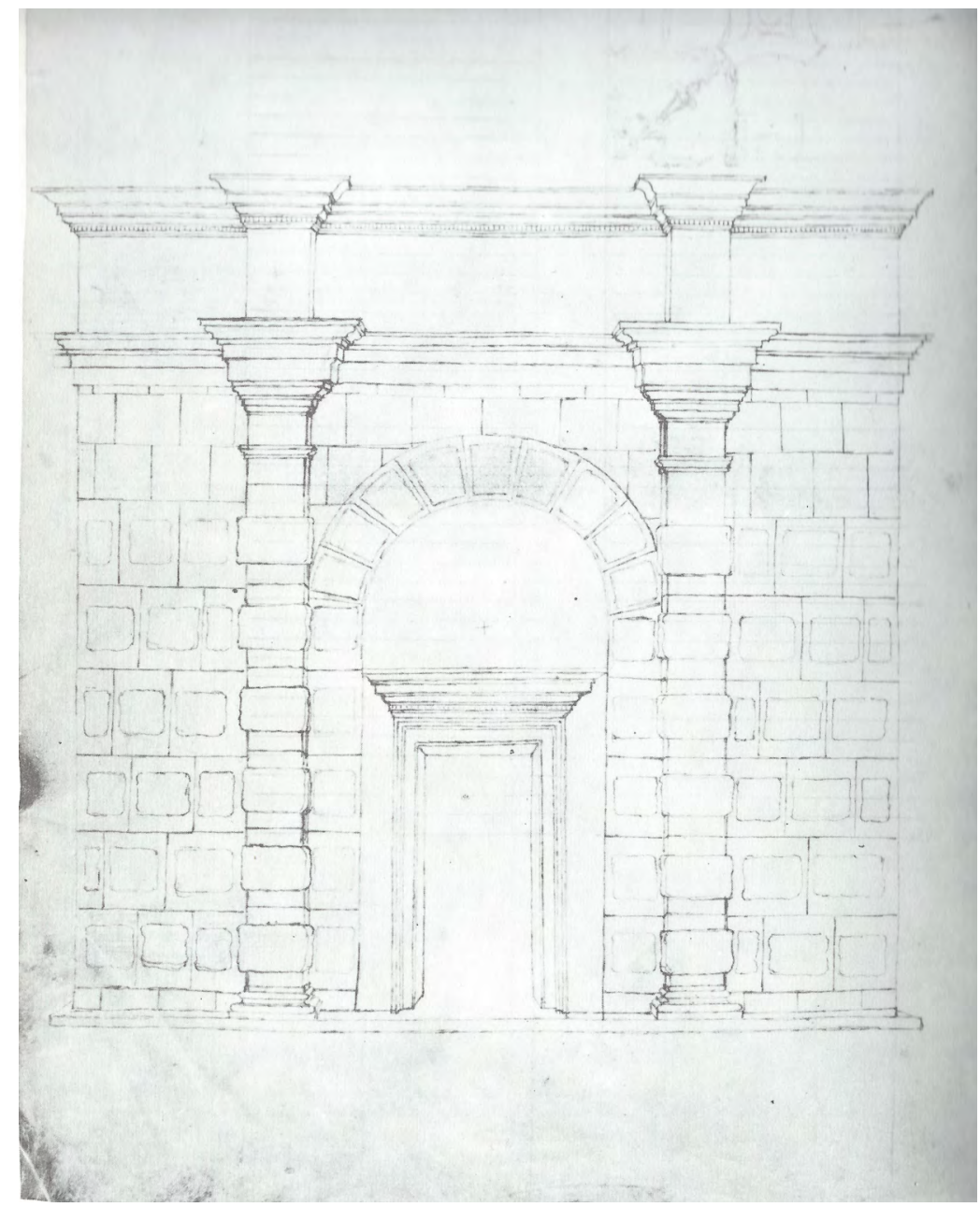

Figura 12 - Francesco di Giorgio Martini - Vista da arcada do templo do Divo Claudio. (Tratatti di Architettura Ingegneria e Arte Miitare. A cura di Corrado Matese, Transcrizione di Livia Matese Degrassi. Tomo I, Codice Torinense Saluzziano 148, f.78v. TAV. 144. Milano: Il Polifilo, 1967). 


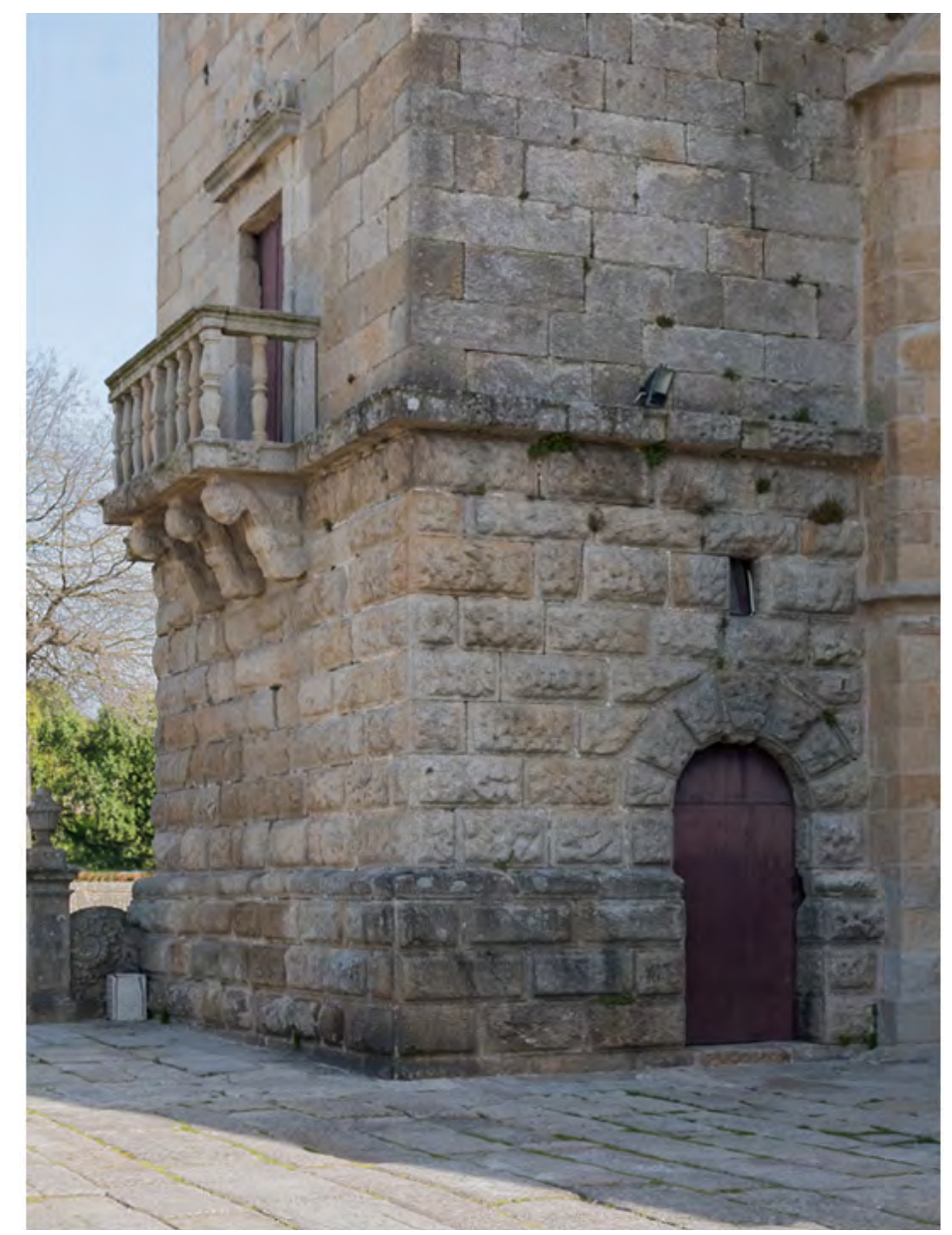

Figura 13 - Face sul do podium da torre, com a porta de acesso ao interior (C) António Sabler).

Terá João Lopes-o-Moço, já na década de setenta, utilizado esse tipo de rusticado na torre? O mesmo mestre deve ser o autor da vizinha sineira da Matriz de Azurara (Ruão, 1996:111), onde não o fez. Para além disso, as duas torres são quase idênticas. É possível, por essa razão, que tivesse herdado um projeto que, como se referiu, se acomodaria mais à primeira metade do século, e os silhares já afeiçoados para ele. É verdade que voltará a utilizar, a partir da década de oitenta, em obras que Ihe são atribuídas em Viana do Castelo, como o convento de S. Domingos ou a fachada do hospital da Misericórdia, o almofadado "à romana". Este, porém, para além de formalmente diverso, terá os valores ornamentais e o tratamento licencioso com que Serlio o conotou, e se afastam já do simbolismo fundacional e estrutural que pode ter estado na origem da sua utilização na torre sineira de Vila do Conde.

\section{Conclusão}

O Paço do Concelho de Vila do Conde é o resultado direto da presença, no Norte do país, do italiano Francisco de Cremona, muratore trazido pelo ex-embaixador do rei D. Manuel I junto da corte papal em Roma, D. Miguel da Silva, quando do seu regresso a Portugal em 1525. Originalmente influenciado pelo tipo de arquitetura "estruturalista" desenvolvida por Francesco di Giorgio em Urbino, o projeto de Cremona para o paço terá sido parcialmente adulterado pela entrega da sua execução a mestres pedreiros ligados à tradição portuguesa. Cremona, e o seu patrono D. Miguel da Silva, foram ainda os responsáveis pela introdução de um gosto antiquário no Norte, mediado mais, uma vez, por Di Giorgio e, também, pelos arquitetos romanos, sobretudo Bramante. O embasamento rusticado da vizinha torre 
da matriz sugere a permanência desse gosto, apesar da época tardia em que foi construído e de subsistirem dúvidas sobre a datação do projeto.

\section{Agradecimentos}

Ao Dr. Pedro Brochado, do Gabinete de Arqueologia da Câmara Municipal de Vila do Conde, pela informação disponibilizada.

Ao Dr. Manuel Real, pela análise dos silhares da base da torre da matriz.

\section{Referências}

ABREU, Susana Matos - A obra do arquitecto Francesco da Cremona (ca. 1480-c.1550) em Portugal. Novas pistas de investigação. In. A encomenda, o artista, a obra. Porto: CEPESE, p. 557-583, 2010.

ADAM, J. - La Construction Romaine. Matériaux et Techniques. França, $2^{\circ}$ ed. (1989)

AFONSO, José Ferrão - Algumas observações sobre Francisco de Cremona, Francesco di Giorgio, os "estudos do antigo" e a arquitectura do Renascimento entre o Douro e o Cávado. Mínia, no 13, IIIa Série, p. 219-248, 2014.

AFONSO, José Ferrão - A Misericórdia da rua das Fores no século XVI. In: Saúde, Ciência e Património. Actas do III Congresso da História da Santa Casa da Misericórdia do Porto. Porto: Santa Casa da Misericórdia do Porto: 2016, p. 297- 332.

Afonso, José Ferrão - Uma arquitectura em diversas maneiras: Francisco de Cremona e o Renascimento do Entre Douro e Cávado. In: D. Miguel da Silva. A Obra ao Tempo. Viseu: DGPG/Mvsev Grão Vasco/Projecto Património, 2015, p. 68-99.

AMORUSO, Giuseppina, et al.- Arquitectura portuguesa no período do Renascimento. Trabalho orientado pelos professores arquitectos Alexandre Alves Costa, Marta Oliveira e José Quintão para a cadeira de História de Arquitectura Portuguesa I, FAUP, 1991.

BASTO, Artur Magalhães - Os diversos paços do concelho da cidade do Porto. In: Idem "Vereaçoens". Anos de 1390-1395. Porto: Câmara Municipal do Porto, Gabinete de História da Cidade, [s.d.], p. 247- 267.

BERTOLOTTI, A.- Artisti lombardi a Roma nei secoli XV, XVI e XVII. [S.I.]: Arnoldo Forni Editore, 1985. Ristampa anastatica dell' edizione di Milano, 1881, 1985.

CAETANO, Carlos Manuel Ferreira - As Casas da Câmara dos Concelhos Portugueses e a Monumentalização do Poder Local (Séculos XIV a XVIII). Tese policopiada, 2 volumes. Tese de Doutoramento apresentada à Faculdade de Ciências Sociais e Humanas da Universidade Nova de Lisboa. Lisboa: Faculdade de Ciências Sociais e Humanas 2011.

DESWARTE, Sylvie - Il "Perfetto Cortegiano" D. Miguel Da Silva. Roma: Bulzoni Editore, 1989.

FIORE, Paolo - L'architettura civile di Francesco di Giorgio. In: Fiore, Paolo e Tafuri, Manfredo (a cura di) - Francesco di Giorgio architetto. Milão: Electa, 1994, p. 74-125.

Freitas, Eugénio de Andrea da Cunha e - Vila do Conde. 2. História e Património. Vila do Conde: Câmara Municipal de Vila do Conde, 2001. 
MOREIRA, Rafael - Arquitectura: Renascimento e Classicismo. In: Pereira, Paulo (dir.) História da Arte portuguesa, Lisboa: Temas \& Debates, vol. II, 1995, p. 303-373.

MOREIRA, Rafael - D. Miguel da Silva e as origens da arquitectura do Renascimento em Portugal. In O Mundo da Arte, 2a Série, nº1, 1988 p. 5-23.

NEVES, Joaquim Pacheco - Vila do Conde. Vila do Conde: Edição da Secção Cultural da Câmara de Vila do Conde, 1987.

OLIVEIRA, Marta Peters Arriscado de - Arquitectura portuguesa do tempo dos Descobrimentos: assento de prática e conselho cerca de 1500. Texto policopiado, 4 vols. Dissertação de doutoramento apresentada à Faculdade de Arquitectura da Universidade do Porto, 2004.

OLIVEIRA, Marta Peters Arriscado de - O Mosteiro do Salvador: um projecto do século XVI. In: Monumentos, 9, 1998, p. 16-25.

RUA, M. H. (1998) - Os Dez Livros de Arquitectura de Vitrúvio. Lisboa: R.B.M. - Artes Gráficas, Lda.

SOUSA, E. S. M. (2013) - Vila do Conde no início da Época Moderna. Construção de uma nova centralidade. Dissertação de Mestrado em Arqueologia, apresentada na Faculdade de Letras da Universidade do Porto

VITERBO, Sousa - Dicionário Historico e Documental dos Architectos, Engenheiros, Constructores Portugueses, Lisboa: Imprensa Nacional Casa da Moeda, vol. I, 1988.

\section{Fontes informatizadas}

Fabião, C. (1995) - "Património arqueológico em Portugal: gestão de uma memória incómoda". [Consulta: 1.02.2017]. Https://www.academia.edu/267976/Patrim\%C3\%B3nio Arqueol\%C3\%B3gico Em Portugal Gest\%C3\%A3o De Uma Mem\%C3\%B3ria InC\%C3\%B3moda

\section{Cúrriculo dos Autores}

\section{José Ferrão Afonso}

Professor auxiliar da Escola das Artes da da Univeridade Católica Portuguesa, Centro Regional do Porto. Investigador do CITAR e do CEAU. Licenciado em História, Variante da Arte pela FAUP. Mestre em História, Variante da Arte, pela FLUP. Doutorado em Teoria e História da Arquitetura pela Escola Técnica Superior de Arquitetura de Barcelona.

Contacto: jafonso@porto.ucp.pt

\section{Guilhermina Cadeco}

Mestranda em Conservação e Restauro na Escola das artes da Universidade católica Portuguesa. Licenciada em Arqueologia pela Universidade do Minho.

Contacto: rios.cadeco@gmail.com 